\title{
Image Quality in Digital Radiographic Systems
}

\author{
Solange Maria de ALMEIDA ${ }^{1}$ \\ Ana Emília Figueiredo de OLIVEIRA ${ }^{2}$ \\ Rívea Inês FERREIRA ${ }^{1}$ \\ Frab Norberto BÓSCOLO${ }^{1}$ \\ ${ }^{1}$ Department of Oral Diagnosis, School of Dentistry, UNICAMP, Piracicaba, SP, Brazil \\ ${ }^{2}$ Department of Oral Radiology, School of Dentistry, Federal University of Maranhão, São Luis, MA, Brazil
}

\begin{abstract}
The aim of the present study was to evaluate the image quality of four direct digital radiographic systems. Radiographs were made of the maxillary central incisor and mandibular left molar regions of a dry skull, and an aluminum step-wedge. The X-ray generator operated at $10 \mathrm{~mA}, 60$ and $70 \mathrm{kVp}$, and images were acquired with 3, 5, 8, 12, 24 and 48 exposure pulses. Six well-trained observers classified the images by means of scores from 1 to 3. Collected data were submitted to nonparametric statistical analysis using Fisher's exact test. Statistical analysis showed significant differences $(\mathrm{p}<0.01)$ in image quality with the four systems. Based on the results, it was possible to conclude that: 1) all of the digital systems presented good performance in producing acceptable images for diagnosis, if the exposures of the step-wedge and the maxillary central incisor region were made at 5 pulses, as well as at 8 pulses for the mandibular left molar region, selecting 60 or $70 \mathrm{kVp} ; 2$ ) higher percentages of acceptable images were obtained with the administration of lower radiation doses in CCD-sensors (charge-coupled device); 3 ) the Storage Phosphor systems produced acceptable images at a large range of exposure settings, that included low, intermediate and high radiation doses.
\end{abstract}

Key Words: dental radiography, digital systems, image quality.

\section{INTRODUCTION}

The conventional intraoral radiographic film remained the only image receptor option for almost a century. However, with the advances in radiology, much research has been done in order to enhance image quality, increase the accuracy of interpretation, reduce radiation dose as well as make it easier to obtain radiographs and decrease the time spent. As a result, direct digital intraoral radiographic systems have become a reality.

In this new imaging modality, the radiographic film is replaced by a sensor for the X-rays. The signal temporarily stored within the sensors is transferred to the computer, which displays an image that may be filed, interpreted, manipulated and quantified. The advantages of the direct digital radiographs are recognized by many authors (1-18). At present, there are two fundamentally different concepts for direct digital image acquisition, the CCD-based (charge-coupled device) and the Storage Phosphor systems.

The CCD-based systems are so-called because they use the CCD as a device for image capturing. In these systems, a chip is used as a sensor for the radiation. A cable connects the sensor to the computer and the image is displayed almost immediately on the monitor after exposure. These sensors are characterized by the reduced dimensions of their active surface in comparison with standard periapical film.

On the other hand, in the Storage Phosphor systems, a photostimulable storage phosphor imaging plate is exposed to radiation and a latent image is stored. The information contained in the plate is released by exposure to a laser scanner. These imaging plates consist of a polyester base coated with a crystalline halide composed of europium-activated barium fluorohalide compounds. When an image plate is irradiated, the absorbed X-ray energy is stored within the phosphor crystals. To read the stored information, a thin collimated helium-neon laser beam scans the surface of the 
image plate; the stored energy is thereby released as fluorescent blue light. This light is detected by a photomultiplier and converted to electric signals, which are subsequently digitized (19). Photostimulable storage phosphor imaging plates are characterized by having dimensions similar to those of the 1.2 periapical film (approximately $30 \times 40 \mathrm{~mm}$ ).

Since the end of the 1980's, direct digital radiographic systems of the CCD and Storage Phosphor types have been launched worldwide. However, recently, with the launching of a new Storage Phosphor system - DenOptix, the authors proposed to develop this study with the objective of making a comparative evaluation of the images produced by two CCD-based and two Storage Phosphor systems, employing a phantom dry skull, however, having fundamentally clinical implications.

\section{MATERIAL AND METHODS}

The radiographic systems evaluated in this research were the following: System 1: DenOptix (Dentsply International/Gendex Dental X-ray Division, Des Plaines, IL); System 2: Digora (Orion Corp./ Soredex, Helsinki, Finland); System 3: CDR, Sensor No. 2 (Schick Technologies, Inc., Long Island City, NY); System 4: Sens-A-Ray 2000 (AFP Imaging/Dent$\mathrm{X}$, Elmsford, NY). Photostimulable storage phosphor imaging plate dimensions, approximately $30 \times 40 \mathrm{~mm}$, were used. The resolution employed for DenOptix was the system standard, which is of 300 dpi. The digital system monitors were S-VGA, plane 17-inch screen and a configuration of $1024 \times 768$ pixels resolution.

The three objects analyzed were two dental anatomical areas of one phantom dry skull, the maxillary central incisor and mandibular left molar regions, that were covered with acrylic material in order to simulate soft tissue, and an aluminum step-wedge.

The dental X-ray unit used was the GE 1000 (General Electric Company, Milwaukee, WI, USA), using 60 and $70 \mathrm{kVp}$, with exposures of 3, 5, 8, 12, 24 and 48 pulses for each selected kilovoltage peak. Therefore, 12 different radiation doses were used. The focal spot-to-image receptor distance was $32 \mathrm{~cm}$. An assessment of the beam entry dose was made in order to evaluate the relationship between exposure time and dose. For this purpose the following equipment was used: ion chamber (Victoreen 06-526; Victoreen Inc.,
Cleveland, OH, USA), X-ray timer (Victoreen 07-457; Victoreen Inc.) and $\mathrm{kVp}$ meter (Unfors Inst. 9002; Unfors Instruments, Billdal, Switzerland). The measurements showed that the dental X-ray unit employed presented accurate results regarding exposure time, kilovoltage peak and dose, with a good linear relationship between radiation dose and exposure time.

In order to take standardized radiographs of the two dental anatomical areas, the sensors were positioned as close as possible to the regions to be imaged. With regard to the aluminum step-wedge, an acrylic workbench was used, with the object positioned in the central part of the sensors, where it was imaged at a vertical angle of $90^{\circ}$ and a horizontal angle of $0^{\circ}$. Each object was imaged 12 times with each system, producing a total of 144 radiographs.

The direct digital radiographic images were examined by six dentists. Four of them were radiologists and two were general practitioners. Five features were chosen for evaluation in the radiographs obtained on the human phantom dry skull: 1) presence of coronal caries; 2) cortical bone; 3) root canal space; 4) root apices; 5) periodontal ligament space. For the aluminum step-wedge, the observers had to identify the number of steps in each image, from the thicker part of aluminum up to the thinner, as well as some perforations present in this object. Observers were asked to score images from 1 to 3 , as follows: 1) radiographic image unacceptable for interpretation; 2) radiographic image useful for interpretation, but not perfect. It could be manipulated to become excellent for diagnosis; 3) radiographic image excellent for diagnosis. To avoid a difference among the observers, they were trained prior to interpretation in order to provide them with guidance on how to work with the systems.

The evaluation was carried out disregarding the dimensional differences of the sensors. Only one image was displayed at a time, and the number of images interpreted by each observer was limited to 36 per day, to avoid visual fatigue, which could impair the analysis. The observers were not informed of the type of digital system under examination. The images were interpreted by the software inherent to their system, and the observers were allowed to adjust only the brightness and contrast of the images. The interpretation was conducted at reduced room lighting and monitor brightness. Collected data were submitted to a nonparametric analysis using Fisher's exact test. 


\section{RESULTS}

According to the nonparametric statistical analysis (Fisher's exact test, $\mathrm{p}<0.01$ ), there were no statistically significant differences in the performance of the four direct digital systems, in terms of the production of excellent images for diagnosis, in the dose intervals shown in Table 1. The images were classified as radiographs with excellent characteristics for diagnosis, therefore, corresponding to score 3 , by the pre-established classification.

Figure 1 summarizes the frequency of images scored 2 and 3 for an estimated range of exposures in which the four systems presented clinically acceptable performance. The graphs plotted in this figure are based upon the percentages of images scored 2 and 3, selecting 60 and $70 \mathrm{kVp}$, with exposures from 3 to 12 pulses. According to these graphs, all systems presented acceptable performance with 5 and 8 exposure pulses, at $60 \mathrm{kVp}$. For beam energy of $70 \mathrm{kVp}$, the systems tended to perform better with exposures of 3 and 5 pulses.

\section{DISCUSSION}

To evaluate the image quality of the systems, it was important that the objects were diversified because different objects tend to demand different exposure times and efficiency levels of the systems to obtain as good as possible image quality. In this way, the analysis situations of this research could be enlarged to provide more reliable results. The choice of a subjective analysis was made because it is a reliable means of obtaining correlation with dental practice.

In general, the results indicated the high sensitiv-

Table 1. Optimal exposure settings for all four direct digital systems.

\begin{tabular}{lcl}
\hline Object & $\begin{array}{c}\text { Kilovoltage peak } \\
(\mathrm{kVp})\end{array}$ & Pulse \\
\hline Step-wedge & 60 & 5 and 8 \\
Step-wedge & 70 & 5 \\
Molar region & 60 & 8 and 12 \\
Molar region & 70 & 5 and 8 \\
Incisor region & 60 & 5 and 8 \\
Incisor region & 70 & 3 and 5 \\
\hline
\end{tabular}

${ }^{*} \mathrm{p}>0.01$ ity of the direct digital systems studied. The acceptable image quality presented by System 2 in this study is in agreement with other research $(2-6,11,12,14)$, and one of the factors that contributed to these results was the photostimulable storage phosphor imaging plate efficiency in detecting the low contrast $(11,12)$. This characteristic is even more important when it is of interest to the observer to examine subtle alterations, and this feature is related to the sensor's efficiency in detecting X-rays photons, which is also responsible for the decrease in background image noise in dental radiographs (11).

Yoshiura et al. (16) pointed out that the detector should have a wide dynamic range, so small differences in attenuation can be detected. This means that the system should produce acceptable images in a large range of dose exposures.

The large dynamic range presented by the photostimulable storage phosphor imaging plates, a characteristic that has already been reported in other studies $(1,2,7-11,13-15,19)$, made it possible for a greater number of images acceptable for diagnosis than with the CCD-based systems, in which the ratio of images with diagnostic value decreased markedly with an increase in exposure time. Gröndahl et al. (2) reported that System 2 image quality is rated high, presumably as an effect of the wide dynamic range of the Storage Phosphor systems.

In fact, it was observed that the Storage Phosphor systems dynamic range was wider than that of the CCD-based system which is in agreement with findings of other authors (1,2,7-11,13-15). Versteeg et al. (13) reported that the primary advantages of storage phosphors are their wide dynamic range, because of the automatic exposure control, and their low dose requirements.

Comparing System 1 to System 2, Borg et al. (19) reported that, when the two systems were used at their default settings, System 1 had a better dose response, a higher contrast index and a higher modulation transfer than System 2; however, System 1 also had higher noise than System 2 at lower exposures. This means that whenever image enhancement algorithms were applied with System 2, performance similar to that of System 1 could be obtained, taking into account that noise was lower for System 2. With respect to the performance of System 2, it is believed that this is mainly due to a function available in its software, which 
is the calibration mode. This command allows System 2 to explore the potentiality of its wide dynamic range by means of an adjustment that makes it possible to program the system, adapting it to a determined exposure time. Versteeg et al. (15) emphasized that System 2 should be calibrated for the highest exposure that is likely to be used in order to exploit its wide latitude to the maximum.

In the present study, the CCD-sensors presented high sensitivity, as they produced acceptable images at the lowest selected doses, despite their narrow dynamic range, in agreement with other research on CCD-based systems $(2,8,9)$. Attaelmanan et al. (17), in a comparative study between two generations of Visualix/Vixa and CDR, were able to state that both CCD-based systems had better resolution at small radiation doses and over a short exposure range, which is in agreement with the present study. At the 12 different doses within

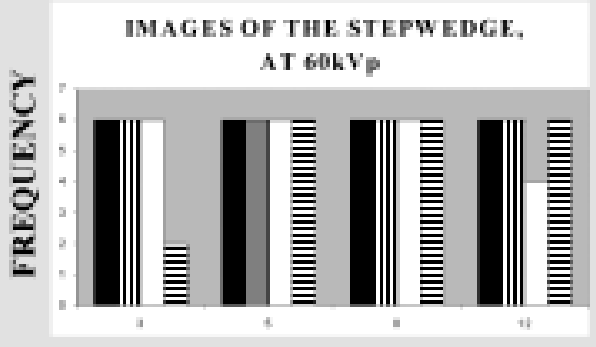

PULSE

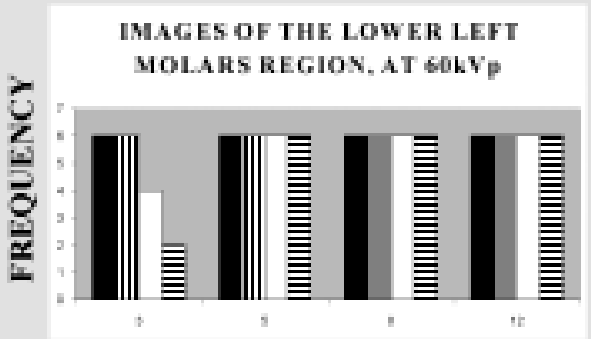

PULSE

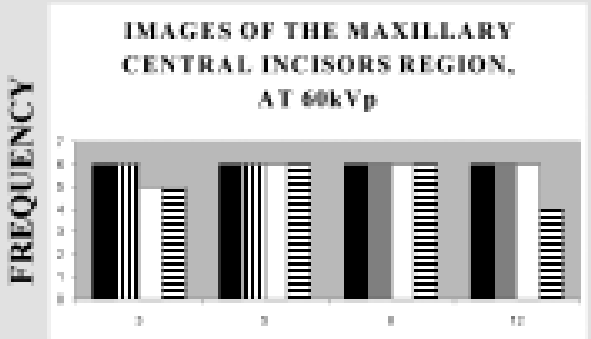

PULSE

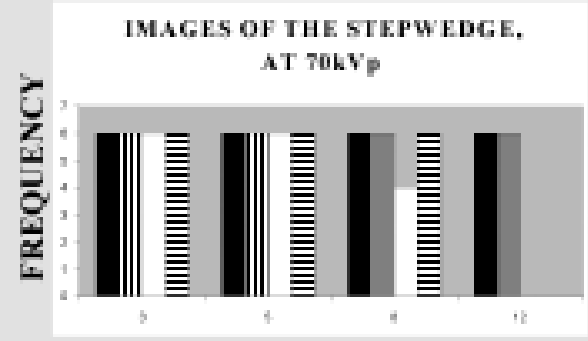

PULSE

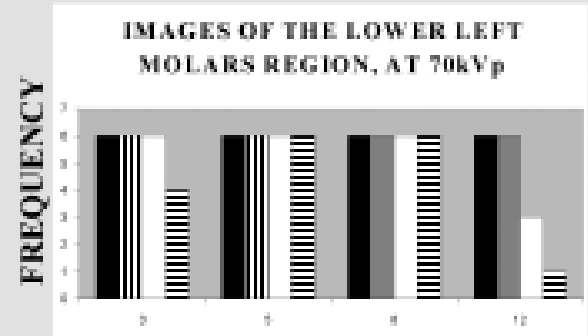

PULSE

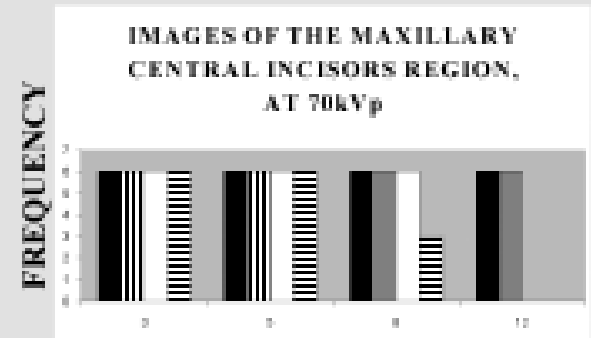

PULSE

\section{- SYSTEM 1 \\ - SYSTEM 2 \\ ㅁYSTEM 3 \\ 曰 SYSTEM 4}

Figure 1. Frequency of digital images scored 2 and 3, with exposures from 3 to 12 pulses, at 60 and $70 \mathrm{kVp}$. System 1: DenOptix; System 2: Digora; System 3: CDR; System 4: Sens-A-Ray 2000. 
a wide range of exposure settings that were used in this study, many images became over-exposed, rendering them without the least possibility of making a diagnosis. It was observed that employing $70 \mathrm{kVp}$, in $\mathrm{CCD}$-sensors, tended to reduce the dynamic range even further.

Huda et al. (11) reported that, for radiographs that are quantum noise limited, improved SNR (signalto-noise ratio) can be obtained from reducing the image noise by increasing the radiation exposure used to create the dental radiographic image with photostimulable storage phosphor imaging plates. However, the dark signal is dependent on the exposure time, and it increases with increased exposure times. In relation to the CCD-based systems, Hayakawa et al. (20) stated that the relationship between the pixel value and the gray level set by default is a linear gray scale for almost all CCD-based intraoral imaging systems; however, the same authors pointed out that the System 3 is capable of working at a wider range of tissue thickness and $\mathrm{kVp}$ settings than System 4, and this fact may be directly related to the greater number of acceptable images for diagnosis provided by the former in comparison to System 4.

Considering the sensitivity of the two Storage Phosphor systems, it was possible to infer that System 1 was more sensitive. This better performance compared to System 2 can be explained by the logarithm function. It lets the professional take images with a given overall density, using an imparted dose about $40 \%$ lower than if a linear scale is used. In addition, a logarithmic gray scale visualizes radiographic objects in a manner that fits the human eye perception better than a linear scale, and is similar to that which film radiography provides.

The authors could state that systems that have the same image acquisition principle tend to present certain similarities in their general characteristics. However, the inherent peculiarity of each manufacturer in endeavoring to perfect some important details may constitute a relevant aspect in the final result of image quality, dynamic range and sensitivity shown by the systems. As a matter of fact, professionals who are willing to purchase a direct digital radiographic system must consider its intrinsic characteristics and search for the one, CCD-based or Storage Phosphor, that performs in accordance with their practical needs.

Finally, on the basis of the results found, it was possible to conclude that: 1) all of the direct digital systems presented good performance in producing acceptable images for diagnosis, if the exposures of the step-wedge and the maxillary central incisor region were made at 5 pulses, as well as at 8 pulses for the mandibular left molar region, selecting 60 or $70 \mathrm{kVp} ; 2$ ) higher percentages of acceptable images were obtained with the administration of lower radiation doses in CCD-sensors, which indicated their higher sensitivity; 3) the Storage Phosphor systems produced acceptable images in a large range of exposure settings, that included low, intermediate and high radiation doses, therefore, presenting a wide dynamic range.

\section{RESUMO}

O presente trabalho teve por finalidade avaliar a qualidade das imagens fornecidas por quatro sistemas radiográficos digitais. Foram tomadas radiografias das regiões de incisivos centrais superiores e molares inferiores esquerdos, de um crânio macerado, e de uma escala de densidade em alumínio. O aparelho de raios $\mathrm{X}$ foi regulado para funcionar com $10 \mathrm{~mA}, 60$ e $70 \mathrm{kVp}$, sendo as imagens obtidas com 3, 5, 8, 12, 24 e 48 pulsos. Seis examinadores devidamente treinados atribuíram notas variando de 1 a 3 às imagens. Os dados coletados foram submetidos a uma análise não paramétrica, utilizando-se o teste exato de Fisher. A análise estatística demonstrou diferenças significantes $(p<0,01)$ na qualidade das imagens fornecidas pelos quatro sistemas. Os resultados permitiram concluir que: 1) todos os sistemas digitais apresentaram bom desempenho na exibição de imagens aceitáveis para diagnóstico, se as exposições da escala de densidade e da região de incisivos fossem realizadas com 5 pulsos, e, com 8 pulsos para a região de molares inferiores, empregando-se $60 \mathrm{ou}$ $70 \mathrm{kVp}$; 2) percentagens maiores de imagens aceitáveis foram obtidas com a aplicação de doses mais baixas nos sensores CCD; 3) os sistemas de armazenamento de fósforo produziram imagens aceitáveis para diagnóstico em uma faixa mais ampla de exposições, que incluía doses de radiação baixas, intermediárias e elevadas.

\section{ACKNOWLEDGEMENT}

This study was partially supported by the Foundation of Research from São Paulo State (FAPESP), Brazil.

\section{REFERENCES}

1. Wenzel A, Gröndahl HG. Direct digital radiography in the dental office. Int Dent J 1995;45:27-34.

2. Gröndahl HG, Wenzel A, Borg E, Tamissalo E. An image plate system for digital intra-oral radiography. Dent Update 1996;23:334-337. 
3. Brettle DS, Workman A, Ellwood RP, Launders JH, Horner K, Davies RM. The imaging performance of a storage phosphor system for dental radiography. Br J Radiol 1996;69:256-261.

4. Conover GL, Hildebolt CF, Yokoyama-Crothers N. Comparison of linear measurements made from storage phosphor and dental radiographs. Dentomaxillofac Radiol 1996;25:268-273.

5. Møystad A, Svanaes DB, Risnes S, Larheim TA, Gröndahl HG. Detection of approximal caries with a storage phosphor system. A comparison of enhanced digital images with dental X-ray film. Dentomaxillofac Radiol 1996;25:202-206.

6. Van der Stelt PF. Digital radiology using the Digora registration technique. Rev Belge Med Dent 1996;51:93-100.

7. Svanaes DB, Møystad A, Risnes S, Larheim TA, Gröndahl HG. Intraoral storage phosphor radiography for approximal caries detection and effect of image magnification: comparison with conventional radiography. Oral Surg Oral Med Oral Pathol Oral Radiol Endod 1996;82:93-100.

8. Borg E, Gröndahl HG. On the dynamic range of different X-ray photon detectors in intra-oral radiography. A comparison of image quality in film, charge-coupled device and storage phosphor systems. Dentomaxillofac Radiol 1996;25:82-88.

9. Farman TT, Farman AG, Scarfe WC, Goldsmith LJ. Optical densities of dental resin composites: a comparison of CCD, storage phosphor and Ektaspeed Plus radiographic film. Gen Dent 1996;44:532-537.

10. Lim KF, Loh EM, Hong YH. Intra-oral computed radiography an in vitro evaluation. J Dent 1996;24:359-364.

11. Huda W, Rill LN, Benn DK, Pettigrew JC. Comparison of a photostimulable phosphor system with film for dental radiology. Oral Surg Oral Med Oral Pathol Oral Radiol Endod 1997;83:725731.

12. Hildebolt CF, Fletcher G, Yokoyama-Crothers N, Conover GL,
Vannier MW. A comparison of the response of storage phosphor and film radiography to small variations in X-ray exposure. Dentomaxillofac Radiol 1997;26:147-151.

13. Versteeg CH, Sanderink GCH, van der Stelt PF. Efficacy of digital intraoral radiography in clinical dentistry. J Dent 1997;25:215-224.

14. Wenzel A. Digital radiography and caries diagnosis. Dentomaxillofac Radiol 1998;27:3-11.

15. Versteeg CH, Sanderink GCH, van Ginkel FC, van der Stelt PF. Effects of calibration and automatic greyscale adjustment on detectability of simulated bone lesions using a storage phosphor system. Dentomaxillofac Radiol 1998;27:240-244.

16. Yoshiura K, Kawazu T, Chikui T, Tatsumi M, Tokumori K, Tanaka T, Kanda S. Assessment of image quality in dental radiography. Part 2 - Optimum exposure conditions for detection of small mass changes in 6 intraoral radiography systems. Oral Surg Oral Med Oral Pathol Oral Radiol Endod 1999;87:123-129.

17. Attaelmanan A, Borg E, Gröndahl HG. Assessments of the physical performance of 2 generations of 2 direct digital intraoral sensors. Oral Surg Oral Med Oral Pathol Oral Radiol Endod 1999;88:517-523.

18. Syriopoulos K, Sanderink GCH, Velders XL, van der Stelt PF. Radiographic detection of approximal caries: a comparison of dental films and digital imaging systems. Dentomaxillofac Radiol 2000;29:312-318.

19. Borg E, Attaelmanan A, Gröndahl HG. Image plate systems differ in physical performance. Oral Surg Oral Med Oral Pathol Oral Radiol Endod 2000;89:118-124.

20. Hayakawa Y, Farman AG, Scarfe WC, Kuroyanagi K, Rumack PM, Schick DB. Optimum exposure ranges for computed dental radiography. Dentomaxillofac Radiol 1996;25:71-75.

Accepted July 12, 2002 


\title{
WHO/FAO Expert Report on Diet and Chronic Disease
}

\author{
Technical Report Series No. 916, 2003
}

This report, released on 23 April 2003, aimed at identifying new recommendations on diet and physical activity to tackle the rapidly increasing burden of chronic diseases worldwide. The report is a critical science-based contribution to development of a global stategy aimed at reducing cardio-vascular diseases, several forms of cancer (including oral cancer), diabetes, obesity, osteoporosis and dental diseases such as dental caries and dental erosion.

Advice is given on ways of changing daily nutritional intake by reducing energyrich foods high in saturated fat and sugar, cutting the amount of salt in the diet, increasing the amount of fresh fruit and vegetables in the diet and undertaking physical activity everyday.

In terms of dental diseases, it is emphasized that dental caries are preventable by limiting the frequency and amount of sugars and by appropriate exposure to fluoride. Erosion of teeth by dietary acids in beverages may lead to tooth destruction and the consumption of sugary soft drinks should be reduced. It is important for developing countries that currently have low consumption of free sugars do not increase consumption levels. For countries with high consumption levels in addition to high incidence of dental caries, it is recommended that national health authorities formulate country- and community-specific goals for reduction in the amount of free sugars aiming towards the recommended maximum of no more that $10 \%$ of energy intake. The frequency of consumption of foods and/or drinks containing free sugars should be limited to a maximum of four times per day.

The report is only the first step in a process that includes consultation with governments as well as other public and private sector stakeholders in all geopgraphical regions.

This report is available from the WHO website:

http://www.who.int/hpr/nutrition/ExpertConsultationGE.htm 